\title{
Desipramine Hydrochloride
}

National Cancer Institute

\section{Source}

National Cancer Institute. Desipramine Hydrochloride. NCI Thesaurus. Code C28979.

The hydrochloride salt form of desipramine, a secondary amine tricyclic antidepressant

(TCA). In the central nervous system (CNS), desipramine hydrochloride blocks the reuptake of neurotransmitters, including norepinephrine and serotonin. This leads to an increase in the amount of these neurotransmitters in the synaptic cleft and prolongs their activities postsynaptically. 